\title{
Para além da legalidade: Direito e antilegalismo na teoria crítica recente
}

\author{
Beyond legality: law and anti-legalism in the recent critical theory
}

Felipe Gonçalves Silva

felipegons@hotmail.com (Universidade Federal do Rio Grande do Sul, Rio Grande do Sul, Brasil)

\begin{abstract}
Resumo: Uma forte tendência "antilegalista” é identificada por William Scheuerman na teoria crítica recente, a qual colocaria em risco o Estado democrático de direito como principal base normativa e campo prático das lutas emancipatórias. Essa tendência, que encontra em Axel Honneth um de seus maiores expoentes, representaria uma ruptura do modelo desenvolvido por Habermas em Facticidade e validade, em benefício da retomada de uma “orientação contrária ao direito" que alimenta a crítica social desde os tempos de Marx. Partindo das objeções de Scheuerman, o artigo pretende explorar os significados do antilegalismo na obra de Honneth, suas linhas de continuidade com a herança teórica que o antecede e sua possível justificação em nome da persistência e vitalidade da crítica social.
\end{abstract}

Palavras-chave: antilegalismo; democracia; reconhecimento; Axel Honneth; Jürgen Habermas.

\begin{abstract}
William Scheuerman finds a vigorous "anti-legalist" tendency in recent critical theory, which jeopardizes the democratic rule of law as the main normative basis and practical field for emancipatory struggles. According to him, this tendency finds in Axel Honneth one of its greatest exponents and represents a rupture with Habermas' Between Facts and Norms in favor of an orientation contrary to the law that feeds social criticism since Marx's times. Starting from the objections to anti-legalism, I would like to explore its possible meanings in Axel Honneth's recent work, the lines of continuity with this former theoretical background, and the motives of its vindication regarding the persistence and vitality of social criticism.
\end{abstract}

Keywords: anti-legalism; democracy; recognition; Axel Honneth; Jürgen Habermas.

Em seu artigo “Recent Frankfurt Critical Theory: Down on Law?”, de 2016, William Scheuerman busca combater tendências antilegalistas na teoria crítica contemporânea encontradas em dois de seus mais notáveis representantes: Nancy Fraser e Axel Honneth. Contra um suposto menosprezo pelo direito e pelo Estado constitucional, Scheuerman defende o modelo habermasiano como aquele que, com maior força e eficácia, “desafiou o anti-legalismo precipitado e a orientação contrária ao direito que se apresentava como lugar-comum da esquerda radical, especialmente dentro do legado marxista" (Scheuerman, 2017, p. 11 [41]). Para 
Scheuerman, Habermas seria responsável por uma mudança de postura significativa em relação ao direito e à democracia constitucional, passando a considerá-los não como instrumento destinado à dominação de classe, mas como o terreno dentro do qual as próprias lutas emancipatórias teriam de ser travadas. Na contramão desse movimento, que ofereceria tanto uma compreensão mais aprofundada do direito moderno quanto formas de justificação mais sólidas às lutas emancipatórias, Axel Honneth e Nancy Fraser representam para ele tendências regressivas que colocariam em risco o marco jurídico-democrático como campo de enraizamento da própria crítica social.

Honneth compartilharia com Fraser a compreensão de que

a teoria crítica contemporânea estaria sucumbindo a preocupações legalistas ou jurídicas que distorcem a natureza da realidade social ao mesmo tempo que traem os fundamentos hegelianos e marxistas da Escola de Frankfurt inicial, fundamentos que ambos trabalharam de maneira bastante impressionante para reconstruir (idem, p. $1[3])$.

Estaria claro para Scheuerman que este movimento faria oposição sobretudo a Habermas, "cujo livro Facticidade e validade - a contribuição individual mais impressionante da teoria crítica recente à teoria política e jurídica - sintetizou de maneira ambiciosa a ética do discurso neokantiana com a teoria do direito e a literatura jurídica de mais alto nível" (idem, ibidem). A partir de Facticidade e validade, segundo ele, poderíamos acompanhar uma produtiva "virada jurídica" no interior dessa herança intelectual, com a recuperação de importantes contribuições até então subvalorizadas (como as de O. Kirchheimer e F. Neumann) e uma quantidade significativa de novos trabalhos sendo dirigidos aos terrenos desafiadores da literatura jurídica e constitucional. Para Scheuerman, que enxerga a si próprio como alvo implícito dos ataques a essa virada jurídica, o enlace produtivo entre teoria crítica e direito estaria sob risco de ser desfeito:

Temo que a atual crítica ao legalismo encoraje recusas descuidadas do que hoje é - e esperamos que continue a ser - um conjunto importante da literatura crítica, uma literatura que tem profundas raízes no trabalho de pensadores da política e do direito da primeira e da segunda gerações da Escola de Frankfurt, como Neumann, Kirchheimer e Habermas. (...) Receio que a atual preocupação com os perigos do “legalismo" impeça a busca contínua dessa agenda valiosa, mas ainda incompleta (idem, p. 11 [40]).

No artigo "Beyond the Law: a response to William Scheuerman", Honneth busca responder às críticas a ele dirigidas, salientando principalmente que as objeções apresentadas expressariam interpretações equivocadas de sua própria obra (Honneth 2017, p. 127). Sem perder de vista os esclarecimentos e as correções feitas ali, gostaria de oferecer uma resposta às preocupações de Scheuerman a partir de 
uma estratégia distinta, enfatizando motivos para um compromisso mais claro e justificado com o anti-legalismo. Se entendermos por esta expressão não o completo abandono do direito, mas uma postura que combate a redução da crítica social a uma gramática estritamente jurídica, então o próprio projeto fundado em Facticidade e validade possui um núcleo antilegalista incontornável. Procuro inicialmente defender que as tendências antilegalistas encontradas por Scheuerman na teoria crítica pós-habermasiana devem ser consideradas não propriamente uma ruptura com o modelo teórico apresentado por Habermas em 1992, mas desenvolvimentos originais de alguns de seus aspectos mais elementares. Sobretudo, buscarei destacar componentes centrais dos trabalhos de Axel Honneth que pretendem aprofundar uma compreensão do direito e dos processos democráticos que encontra suas bases na infraestrutura comunicativa da vida social. Na sequência, busco assinalar certos problemas autênticos que merecem ser computados ao desenvolvimento teórico de Axel Honneth sob o ponto de vista de uma análise não legalista do direito e da democracia, os quais, entretanto, diferem significativamente das preocupações centrais apresentadas em “Recent Frankfurt Critical Theory: Down on Law?”. Por fim, defendo que certas intuições antilegalistas poderiam auxiliar Scheuerman no desenvolvimento de algumas de suas questões teóricas mais centrais, dando especial atenção a sua produção recente sobre a desobediência civil. Admitindo neste conceito a referência necessária a uma normatividade que se encontra para além do direito positivo, a conclusão busca mostrar que a cruzada antilegalista de Scheuerman encontra-se em descompasso com os próprios referenciais teóricos defendidos em sua obra Civil Disobedience (2018), gerando sobretudo dificuldades à pretendida atualização desta categoria à luz da experiência política recente.

I.

Facticidade e validade não tem início com a reconstrução discursiva do sistema de direitos, nem com análises sobre os fundamentos e desafios da rule of law, da separação de poderes ou da jurisprudência constitucional. Embora venha a tratar dessas e de outras questões vinculadas à literatura jurídica especializada, Habermas se dedica antes disso a uma longa apreciação sobre a estrutura da ação comunicativa, remetendo-nos a uma tensão entre facticidade e validade inscrita nos pressupostos pragmáticos da comunicação cotidiana, bem como ao modo com que essa tensão altera as condições de integração social ao longo dos processos históricos de modernização. Ainda que não possamos retomar esse longo percurso levado a cabo no primeiro capítulo, cabe nele frisar alguns pontos decisivos para toda a obra. Em primeiro lugar, é importante destacar que a escolha do direito como objeto de análise e seu modo próprio de investigação são justificados a partir de um 
problema tipicamente sociológico, qual seja, a necessidade de se compreender as condições de integração social no contexto da modernidade. Essa questão, por sua vez, é acessada a partir de uma tensão encontrada na infraestrutura comunicativa da vida social; mais especificamente, a partir de um contraste entre a facticidade das condições concretas de comunicações atuais e a idealidade de pressupostos pragmáticos vinculados à expectativa de uma "comunicação livre de dominação" (Habermas, 1992, p. 42 ss. [p. 57]). Em segundo lugar, é importante lembrar que Habermas enxerga a modernização como um processo caracterizado pela ampliação dos aspectos da vida cotidiana submetidos ao questionamento comunicativo; isto é, a uma crítica intramundana portadora de "caráter explosivo" e potencialmente capaz de reconfigurar pontualmente o estoque de saberes culturais, das instituições sociais e das estruturas de personalidade segundo os termos do entendimento comunicativo. Ao mesmo tempo, a modernização seria marcada por uma crescente diferenciação sistêmica, a qual passa a promover a coordenação social através de um tipo novo de imunização discursiva: não mais a autoridade impositiva do sagrado, mas os meios deslinguistificados do dinheiro e do poder burocrático (idem, pp. 4445 [pp. 61-62]). Por último, cabe insistir no modo muito particular como o direito é inserido nessa exposição: para Habermas, o direito moderno incorpora a referida tensão entre facticidade e validade de modo a permanecer vinculado tanto ao tipo de solidariedade própria do entendimento comunicativo quanto a recursos tipicamente sistêmicos, mostrando-se dependente de ambos. Essa ambivalência do direito, por sua vez, explica seu papel privilegiado nas condições históricas de integração da sociedade moderna, já que permite estabilizar expectativas de conduta por meios coercitivos sem impedir por princípio a circulação da força crítico-transformadora do poder comunicativo (idem, pp. 56-57 [pp. 73-74]). Com isso, apesar de toda sua importância na resposta dada por Habermas ao problema da integração social, o sistema jurídico não oferece um dispositivo isolado e autossuficiente para a compreensão das dinâmicas complexas da sociedade moderna: ele merece ser visto como um meio de integração social entre outros, além de depender profundamente de recursos que não produz por si mesmo.

O direito moderno se alimenta de uma solidariedade que se concentra no papel de cidadão e que, em última instância, tem origem na ação comunicativa. Como veremos, a liberdade comunicativa dos cidadãos pode assumir a forma de uma práxis organizada de autodeterminação mediada por instituições e procedimentos jurídicos; entretanto, ela não pode ser completamente substituída pelo direito coercitivo (idem, p. 52 [p. 69]).

Mais importante para Habermas, entretanto, é afirmar a profunda ambiguidade do direito de um ponto de vista crítico: sua dualidade o permite servir tanto à estruturação de formas comunicativas necessárias à autodeterminação individual e 
coletiva, quanto à institucionalização de imperativos sistêmicos segundo o manto da legitimação jurídica (idem, p. 59 [p. 76]). Desse modo, a avaliação de suas possibilidades e riscos exige uma abordagem do direito que não oculte a ambivalência de seus aspectos de validade. Isso marcará profundamente as duas dimensões reconstrutivas operadas ao longo da obra: na primeira parte, dedicada à tensão entre facticidade e validade interna ao direito, somos conduzidos a uma crítica dos diferentes modos de compreensão que reduzem a validade jurídica tanto a fontes normativas substanciais (vinculada ao direito natural, à rule of law ou a valores políticos compartilhados) quando à facticidade de sua positivação legal. Nesse último sentido, o positivismo jurídico é duramente combatido por reduzir a base de validade do direito a um procedimento autorreferencial depurado de qualquer exigência de justiça ou correção normativa, acabando por simplesmente endossar o ato de vontade do legislador político. Com o intuito de neutralizar o direito contra determinações exteriores, o positivismo assumiria a posição legalista de encerrar artificialmente o sistema jurídico em si mesmo e abandonar as fontes que alimentam sua normatividade própria - dissolvendo, ironicamente, as fronteiras entre direito e política:

A redução das normas jurídicas a ordens do legislador político significaria que o direito moderno se dissolve em política (...) Na medida em que a validade do direito é desligada de qualquer referência aos aspectos da justiça ou correção normativa, os quais transcendem as decisões do legislador, a identidade do direito torna-se extremamente difusa. Pois desse modo desapareceriam, nomeadamente, os pontos de vista legitimadores sob os quais o sistema jurídico torna-se comprometido a manter a estrutura do medium do direito (idem, p. 587 [p. 610]).

Um problema similar é encontrado também nas práticas de aplicação normativa. Neste ponto, a posição positivista atribuiria a juízes um grande espaço para o exercício de um juízo pessoal discursivamente não controlado, seja desonerando decisões tomadas no interior de uma "moldura interpretativa" vaga, seja autorizando o arbítrio judicial nos casos de "penumbra" ou indeterminação de sentido. Mais uma vez, tentando resguardar a neutralidade do direito em relação a exigências normativas extrajurídicas, a postura positivista faz com que o direito se dilua em formas variadas de decisionismo, agora não mais do legislador político, mas de juízes e aplicadores do direito.

[Kelsen e Hart] enfatizam o fechamento e a autonomia de um sistema jurídico impermeável a princípios extrajurídicos. O problema da racionalidade é com isso resolvido em favor da primazia de uma história institucional delimitada estritamente e purificada de qualquer fundamento de validade suprapositivo. (...) A interpretação positivista da prática das decisões judiciais faz com que a segurança jurídica obscureça a garantia de correção normativa. (...) Hart atribui a necessidade de interpretação das normas jurídicas à estrutura fundamentalmente aberta das linguagens naturais e chega a uma conclusão decisionista. Na medida em que o direito válido não apresenta 
uma determinação suficientemente precisa de um estado de coisas, o juiz se vê obrigado a decidir segundo sua própria discricionariedade (idem, pp. 247-248 [p. 262]).

Para Habermas, ainda que estruturada por procedimentos legalmente previstos, a legitimidade do direito teria de se alimentar de fontes comunicativas irredutíveis ao conhecimento técnico dos juristas e que perpassa todos os âmbitos da criação e aplicação normativa. Em outras palavras, a legitimidade do direito exige que os procedimentos jurídicos, em seus diferentes níveis de institucionalização, encontremse submetidos às constrições racionalizadoras de um discurso racional prático, cujas exigências extrapolam o saber técnico e a linguagem especializada dos operadores do direito. Nesse sentido, a chamada "reconstrução interna" é perpassada por críticas a tentativas de ocultamento da ambivalência própria do direito, encontradas naquilo que poderíamos chamar de "absolutizações" unilaterais de um dos componentes da tensão entre validade e validade - as quais ofereceriam não apenas compreensões inadequadas do direito como, sobretudo, bases justificatórias para práticas jurídicas autoritárias.

$\mathrm{Na}$ segunda dimensão reconstrutiva, o direito é lido em sua função de mediação entre sociedade civil e sistema político, sendo apresentado como estruturação formal de esferas comunicativas que geram condições necessárias à circulação dos fluxos comunicativos que emergem da sociedade civil. Sua concepção de democracia deliberativa exigirá que a legitimidade do Estado democrático de direito seja pensada como um processo de formação coletiva da opinião e da vontade que encontra suas fontes em comunicações espontâneas enraizadas na sociedade civil. Portanto, esse segundo momento como um todo pode ser considerado exigência de uma análise antilegalista, já que salienta a necessidade de se verificar uma tensão entre facticidade e validade externa ao direito (isto é, entre expectativas democráticas que habitam a sociedade civil e o caráter tendencialmente hermético do sistema político). Mas a tese antilegalista central que acompanha todo o livro, isto é, a incapacidade do direito cumprir suas exigências tanto normativas quanto funcionais segundo recursos próprios, recebe aqui uma formulação nova e específica: ela se traduz em um modo de apresentação da "esfera pública" - um dos conceitos mais centrais do pensamento político habermasiano - que ressalta seu caráter fluido, espontâneo, não completamente organizável e, sobretudo, incapaz de ser produzido ou plenamente assegurado em termos estritamente jurídicos. Nesse sentido mesmo, Habermas escreve que sua teoria possui um cerne "anárquico":

Aquele potencial das liberdades comunicativas desencadeadas possui certamente um cerne anárquico, do qual as instituições do Estado democrático de direito precisam se alimentar caso queiram efetivamente garantir liberdades subjetivas iguais (idem, p. $10[27])$. 
As garantias dos direitos fundamentais não são capazes de proteger sozinhas a esfera pública e a sociedade civil contra deformações. Muito antes disso, as estruturas comunicativas da esfera pública precisam ser mantidas intactas por uma sociedade civil ativa. Na medida em que a esfera pública política precisa em certo sentido estabilizar a si mesma, revela-se a notável autorreferencialidade da práxis comunicativa da sociedade civil (idem, p. 447 [p. 469]).

No artigo "Beyond the Law: a response to William Scheuerman", Honneth lamenta a "ênfase exagerada" dada às estruturas jurídicas desde o início dos anos 1990 tanto pela teoria crítica quanto por outras importantes heranças intelectuais dedicadas ao problema da justiça social (Honneth, 2017, 126). Para ele, entretanto, essa transformação possuiria um impacto mais destrutivo na teoria crítica, já que representa um abandono de seu comprometimento originário com a interdisciplinaridade e com a expectativa de apreender a diversidade dos traços elementares que marcam a vida social em um determinado período histórico. Um sintoma desse abandono seria o afastamento de disciplinas anteriormente importantes na cooperação interdisciplinar, como a psicanálise e a estética, bem como a negligência em relação a temas centrais de nosso presente, como "a transformação estrutural do trabalho social, o crescimento imperceptível da exclusão social, o papel de afetos inconscientes no processo de integração política, as rápidas transformações no formato da indústria cultural, a passagem da acumulação capitalista à esfera financeira e a crescente importância do mercado para a produção artística" (idem, ibidem). Desse modo, ao invés de buscar desfazer a impressão gerada em autores como Scheuerman, Honneth insiste que sua obra expressa sim um descontentamento com a "fixação unilateral" da teoria crítica recente a questões estritamente jurídicas, o que cumpriria um efeito excludente ou de clivagem: "os únicos [problemas sociais] remanescentes parecem ser aqueles que podem ser tratados pela perspectiva do sistema jurídico-democrático" (idem, ibidem).

Honneth atribui essa fixação unilateral não a Habermas ele mesmo, mas às interpretações habermasianas prevalecentes desde o início dos anos 1990. Diferentemente disso, ele chama atenção para a necessidade de se compreender os estudos de Habermas sobre o direito e a democracia como contribuições conectadas ao quadro anterior de sua teoria da ação comunicativa, o que, segundo ele, afasta a referida unilateralidade e vincula o sistema jurídico ao funcionamento mais amplo da reprodução social:

Esse tipo de unilateralidade certamente não pode ser atribuído a Facticidade $e$ validade, de Jürgen Habermas. (...) Este estudo de teoria jurídica guarda em si os resultados de sua monumental Teoria da Ação Comunicativa. (...) Eu não vejo qualquer razão para pensar que Habermas pretendia que a teoria jurídica deste 
livro simplesmente substituísse sua análise social anterior mais abrangente. Mas isso parece ter sido justamente aquilo que alguns de meus colegas acreditavam quando decidiram limitar as preocupações da teoria crítica à resolução dos problemas com os quais o sistema jurídico se vê confrontado (idem, p. 127).

Desse modo, muito embora já tenha objetado a excessiva centralidade dada por Habermas à reconstrução do Estado democrático de direito (Honneth, 2011, p. 111; Honneth, 2007), Honneth o exime aqui da responsabilidade pelos direcionamentos legalistas que encontra no interior da teoria crítica recente. Estes seriam fruto de desenvolvimentos posteriores, próprios de uma interpretação limitadora de Facticidade e validade que desfaz o vínculo entre análise jurídica e crítica social. Nesse sentido, como veremos, o plano de repostas privilegiado por Honneth em "Beyond the Law: a response to William Scheuerman" salienta aproximações significativas de sua abordagem jurídica com alguns dos elementos mais centrais de Facticidade $e$ validade. À luz de suas respostas às críticas dirigidas por Scheuerman, gostaria de destacar o papel atribuído ao direito tanto em Luta por reconhecimento (1992) quanto em $O$ direito da liberdade (2011), salientando duas estratégias distintas de inserir a gramática jurídica como um elemento constitutivo, embora não exclusivo (e tampouco autossuficiente) das fontes normativas da vida social.

Em Luta por reconhecimento. A gramática moral dos conflitos sociais (1992), o direito é tratado como uma das dimensões fundamentais do reconhecimento, figurando assim como um importante elemento das estruturas de personalidade que compõem a autocompreensão normativa do sujeito moderno. Isso não significa que o direito não possua uma realidade objetiva como parte das regras e estruturas que constituem a vida social. No entanto, na tentativa de desenvolver uma "fenomenologia empiricamente controlada", a ênfase das análises sobre o direito moderno é colocada em seu papel exercido nos processos de formação de sujeitos autônomos e individuados: de um ponto de vista fenomenológico, o direito ampliaria o circuito social do reconhecimento para além das relações amorosas, inserindo uma expectativa intersubjetiva baseada no respeito recíproco entre pessoas jurídicas em princípio anônimas. Quer dizer, o reconhecimento jurídico promove uma forma de respeito igualitário entre todos os membros da sociedade, o qual independe das relações de afeto ou predileção que marcam os círculos restritos entre biografias singularizadas que compartilham laços afetivos fortes, dirigindo-se a "propriedades universais" atribuídas a todo ser humano indistintamente (Honneth, 2003, p. 187). Essas propriedades, por sua vez, possuem alargamentos históricos substanciais que partem da autonomia decisória requerida para a celebração de acordos racionais, são ampliados com a capacidade de participação em processos públicos de formação da vontade e alcançam, enfim, a exigência de condições de formação cultural e segurança econômica necessárias ao exercício igualitário das liberdades jurídicas 
formalmente asseguradas (idem, p. 193). Para Honneth, a internalização das expectativas de respeito jurídico é vista como condição mesma ao desenvolvimento de uma forma particular de autorrelação prática, a partir da qual o próprio sujeito aprende a identificar em si as mesmas capacidades racionais reconhecidas nos demais membros da sociedade (idem, p. 194).

É importante sobretudo destacar que esse modo próprio de apreensão do desenvolvimento histórico do direito, vinculado à ampliação das expectativas que alimentam a autocompreensão normativa do sujeito moderno, encontra-se situado no interior de uma teoria da luta social normativamente motivada. Vale dizer, Honneth não pretende elaborar uma teoria do direito em sentido amplo; suas considerações jurídicas são inteiramente dedicadas ao objetivo estrito de demonstrar o papel cumprido pelo direito moderno na formação da gramática moral dos conflitos sociais - o que é feito por meio de um circuito que combina a formação da identidade pessoal por meio da internalização das expectativas normativas de respeito igualitário, o sofrimento gerado por formas sistemáticas de seu desrespeito e a luta motivada pela ampliação das estruturas de reconhecimento factualmente existentes (idem, pp. 257 ss.). Em uma formulação posterior, esse circuito é visto não como uma completa ruptura em relação ao modelo habermasiano, mas como o aprofundamento do tipo de experiência pré-científica capaz de fundar normativamente uma "transcendência intramundana": não as "condições racionais de um processo de entendimento livre de dominação", mas as “condições intersubjetivas do desenvolvimento da identidade humana", as quais poderiam ser encontradas nas "formas sociais de comunicação em que o indivíduo cresce, adquire uma identidade social e, em última instância, precisa aprender a conceber a si mesmo como um membro igual e único da sociedade" (Honneth 2007b, p.74).

Para Honneth, entretanto, apesar desse papel importante atribuído ao reconhecimento jurídico na dinâmica das lutas sociais, ele é incapaz de oferecer sozinho a gramática do reconhecimento em sua completude. Isso porque as bases normativas da formação da identidade (e da resistência contra seu desrespeito social) trazem uma dupla exigência de igualdade e individuação. 0 direito reconhece capacidades racionais igualmente atribuídas a todo ser humano, podendo mesmo oferecer condições de possibilidade para práticas sociais pautadas na singularidade dos agentes. Mas apenas a estima social é vista como capaz de oferecer um tipo de reconhecimento voltado à particularidade dos sujeitos envolvidos, dirigido às realizações de cada um como parte de um grupo e suas respectivas contribuições à cooperação social (Honneth, 2003, p. 199).

A especificidade do tratamento jurídico aqui empreendido, isto é, sua delimitação segundo os contornos de uma teoria da luta social, está longe de ser levada plenamente em consideração pela leitura de Scheuerman, que exige o 
posicionamento de Honneth acerca de uma extensa lista de tópicos que compõem uma teoria do direito em sentido amplo (sistema de direitos, divisão de poderes, rule of law, etc.). Além disso, Scheuerman encontra em Luta por reconhecimento uma oscilação entre a consideração do direito como um "modo de reconhecimento" abrangente que perpassa toda a vida social e como uma "esfera social" independente e espacialmente delimitada. Para ele, as principais debilidades do tratamento jurídico nesta obra seriam derivadas de seu apego ao segundo desses sentidos específicos: Scheuerman atribui a Honneth uma visão "compartimentalizada" do direito, isto é, uma compreensão do direito como "uma esfera social específica, ocupando um lugar social separado e, em aspectos cruciais, um lugar qualitativamente distinguível de esferas sociais alternativas que, ao menos em princípio, seriam mal atendidas se, de alguma maneira, a legalização [legalization] invadisse essas esferas ou suas lógicas autônomas independentes" (Scheuerman, 2017, p. 3 [10]).

Para Scheuerman, essa visão compartimentalizada do direito não apenas distorce seu papel em diferentes áreas da experiência social, como o coloca perigosamente em "quarentena", exigindo que seja isolado das demais esferas sob pena da destruição de suas respectivas lógicas próprias. Desse modo, o apego de Honneth a uma versão compartimentalizada do direito seria responsável pelo reavivamento de intuições equivocadas vinculadas à "crítica da juridificação", ${ }^{2} 2$ modelo de crítica social utilizado por Habermas em sua Teoria da ação comunicativa (1981) e, segundo Scheuerman, abandonado por bons motivos em Facticidade e validade. Independentemente do mérito de sua rejeição absoluta à crítica da juridificação (para a qual não apresenta argumentos substanciais que fossem além da indicação de obras clássicas, porém, não analisadas), não parece plausível que ela tenha espaço em Luta por reconhecimento. Ainda que faça uso da expressão "esferas sociais", a embocadura fenomenológica não tem seu foco na reconstrução de estruturas sociais objetivas, delimitáveis espacialmente ou segundo lógicas próprias, mas, como vimos, em formações subjetivas e suas potenciais lesões proeminentes. Além disso, o direito é considerado legitimamente inscrito nas esferas do amor e da estima social, respectivamente, como proteções necessárias à integridade pessoal e às condições intersubjetivas de solidariedade pós-tradicional (Honneth, 2003, p. 278).

A respeito dos limites atribuídos por Honneth à gramática jurídica, Scheuerman apresenta ainda o argumento de que a materialização do direito faria com que o sistema

\footnotetext{
1 Para Scheuerman, embora Honneth utilize explicitamente o termo "juridificação" apenas em 0 direito da liberdade, já encontraríamos em Luta por reconhecimento a premissa de que "precisamos resguardar a autonomia das esferas sociais e dos tipos de reconhecimento não-jurídicos contra invasões ‘legalistas' potencialmente perigosas e inapropriadas” (Scheuerman, p. 3 [10]).

2 Para um estudo aprofundado do conceito de juridificação, conferir o excelente trabalho de Tavolari (2019), Origens da juridificação: direito e teoria crítica.
} 
jurídico passasse a reconhecer em seu interior a especificidade de grupos e condições sociais. Com isso, não seria necessária outra forma de reconhecimento para cumprir a exigência de respeito à particularidade dos sujeitos, uma vez que o direito material cumpriria de modo satisfatório este papel: ele teria como característica precípua reconhecer a especificidade das condições particulares de exercício da autonomia (Scheuerman, 2017, p. 10 [37]). Mais uma vez, essa objeção parece negligenciar detalhes importantes da teoria do reconhecimento. A materialização tem o papel importante de incorporar a exigência de igualdade de condições no exercício das competências asseguradas pelo direito formal. Ainda assim, trata-se de assegurar a igualdade de exercício do direito entre todos, não a especificidade de indivíduos em suas contribuições sociais e formas de vida particulares. Além disso, o direito material é especialmente focado na superação de carências ou necessidades particulares que impedem o exercício igualitário da autonomia jurídica. Nesse sentido, a especificidade reconhecida aqui é a das carências, não a das qualidades e realizações particulares de cada um. Com isso, o direito material busca assegurar as condições universais de autonomia e não o reconhecimento de contribuições particulares já cumpridas, mas subvalorizadas, no interior de uma hierarquia particular de valores.

Em O direito da liberdade: Fundamentos de uma eticidade democrática (2011), encontramos um projeto teórico bastante distinto, o qual pretende oferecer as bases para uma teoria da justiça dirigida às instituições e suas correspondentes práticas sociais. Nesse projeto, o conceito geral de direito (das Recht) nos é apresentado como "tudo aquilo que, na realidade social, possui durabilidade moral e legitimidade por servir à possibilidade geral e efetivação da liberdade individual" (Honneth, 2011, p. 16). A partir desse conceito amplo, que distingue "possibilidade geral" e "efetivação" da liberdade, o direito positivo é submetido a um tratamento mais complexo e diversificado, como componentes situados no interior de uma malha abrangente e descentralizada de fontes normativas corporificadas institucionalmente. Sua reconstrução do ordenamento jurídico tem início com a configuração da "liberdade jurídica" por meio de direitos subjetivos privados, apreendida então como a liberdade negativa para se retirar voluntariamente dos contextos comunicativos de modo a permitir ao sujeito definir e repensar suas orientações de valor individuais segundo uma autorreflexão aliviada dos deveres e laços sociais (idem, pp.132 ss.). Sua reconstrução avança à análise dos direitos sociais como tentativas de garantir condições materiais necessárias ao exercício igualitário da liberdade jurídica (idem, p. 143) e, posteriormente, passa a considerações dos direitos subjetivos públicos que estruturam a possibilidade de cooperação dos cidadãos em processos deliberativos dirigidos à formação coletiva da vontade (idem, p. 474 ss). Na seção final do livro, Honneth nos diz que o direito positivo é capaz de recobrir todos os âmbitos de liberdade social com garantias institucionais supervenientes, as quais denotam o 
comprometimento da comunidade jurídica com as transformações decorridas no interior das esferas de relações pessoais, do mercado e da formação democrática da vontade - as quais, enquanto esferas da eticidade, promovem a liberdade social através da cooperação entre subjetividades que se formam e interagem por seu meio (idem, p. 613).

Desse modo, a reconstrução do ordenamento jurídico é marcada por uma polaridade já mencionada no conceito mais abrangente de direito, na medida em que serve aos papéis distintos de possibilidade geral e efetivação da liberdade individual (idem, p. 16). No primeiro desses polos, o direito possibilita a liberdade individual na medida em que permite ao indivíduo suspender sua adesão a contextos particulares da vida ética e promove condições institucionais para um tipo de reflexão autocentrada. No entanto, a obra é perpassada pela tese de que embora a liberdade individual deva ser admitida como bem supremo na modernidade, sua efetivação exige relações de cooperação travadas no interior das instituições da eticidade, por meio das quais "os fins das partes envolvidas se complementam de modo a buscarem satisfação por meio de sua execução complementar" (idem, p. 92). Em função disso, para Honneth, a figura inicial da liberdade jurídica deve ser considerada limitada, já que "é incapaz de gerar e manter as condições de sua própria existência"; vale dizer, promove a liberdade individual em um sentido meramente disruptivo, permitindo o distanciamento momentâneo de interações éticas sem as quais não possui "sustentabilidade" e "razão de existência" (idem, p. 156). E nesse sentido mesmo, não deve ser "absolutizada" nem como padrão único de liberdade, nem como imagem da vida social. Para Honneth, esse tipo de unilateralização seria responsável por patologias sociais significativas vinculadas à postergação contínua dos deveres intersubjetivos e dos laços de cooperação, levando a deformações no modo como os indivíduos se relacionam consigo mesmos e com o mundo social (idem, pp. 157-159).

Pode parecer inconsistente o fato de Honneth trabalhar a liberdade jurídica de forma negativa e potencialmente patológica no início de sua reconstrução e posteriormente, na seção final do livro, vincular o direito à dimensão "mais elevada" da liberdade social (Scheuerman, 2016, p. 5 ss. [17]). Segundo a dinâmica interna da obra, entretanto, não haveria nisso inconsistência, mas um modo intencional de apresentação teórica que se inicia com a forma mais abstrata e negativa da liberdade (a "liberdade jurídica") para posteriormente apreendê-la de modo "substancial" ou "efetivo" - isto é, mostrando suas relações progressivamente mais densas com a eticidade. Nesse sentido, por exemplo, os direitos políticos irão cumprir um papel fundamental na institucionalização da vida pública democrática, a qual exige práticas de cooperação deliberativa que pressupõem, mas não podem ser reduzidas à atitude autorreflexiva do sujeito individual. Nos próprios termos da obra, portanto, o direito 
não estaria limitado estritamente à configuração da liberdade jurídica, mas também possui um papel constitutivo na promoção da liberdade social (Honneth, 2011, p. 613). O vínculo necessário entre essas duas formas de liberdade, entretanto, não é fundamentado ele mesmo a partir de um princípio normativo independente (como no caso do "Princípio do Discurso" habermasiano), mas defendido através de um longo percurso de exposição das bases histórico-sociais de efetivação da liberdade, apreendidas como desenvolvimento do conjunto das instituições que compõem a eticidade democrática. Nesse sentido, ao ver seu modo próprio de compreensão do direito contrastado com aquele desenvolvido em Facticidade e validade, Honneth afirma que ambos coincidem em dois pontos elementares: na consideração da autonomia privada como núcleo estrutural da liberdade jurídica e na necessidade de ser complementada por uma forma de liberdade baseada em práticas coletivas de formação pública da vontade (Honneth, 2017, pp. 128-129). Com isso, a polaridade entre os dois sentidos da liberdade promovida juridicamente coincidiria com a tese habermasiana da cooriginariedade em seus termos centrais, com a diferença significativa de que em $O$ direito da liberdade vemos salientada a necessidade de uma mediação social mais contundente entre essas formas de autonomia, o que justificaria seu distanciamento na ordem expositiva:

Assim, como sua [Habermas] famosa formulação, a autonomia individual e coletiva são "equiprimordiais" no sentido de que tanto o direito à legislação democrática quanto à autonomia privada podem ser constituídos apenas conjuntamente. Eu busquei, por princípio, proceder de modo semelhante em $O$ direito da liberdade, com a exceção de que minha metodologia, seguindo Hegel, separa os dois aspectos da autonomia, colocando autonomia privada - a Willkuerfreiheit de Kant, ou liberdade de escolha - no início de toda a minha reconstrução da eticidade democrática, enquanto que a autonomia coletiva, ou seja, a determinação coletiva do conteúdo dos direitos subjetivos, é apresentada apenas no final do capítulo sobre a esfera pública democrática (Honneth, 2017, p.129).

Em virtude de sua vinculação a esses dois sentidos de liberdade, a leitura "compartimentalizada" do direito (que representa a objeção mais central de Scheuerman) parece aqui mais uma vez pouco convincente ou impactante. Enquanto institucionalização da liberdade jurídica, o direito é visto como uma dimensão não-substancial da vida social, vale dizer, como a possibilidade de suspender momentaneamente os laços intersubjetivos sem determinar, por si mesmo, novos padrões positivos para a orientação do comportamento. Por outro lado, enquanto institucionalização da liberdade social, o direito é visto como um recurso disponível ao longo de toda a extensão da eticidade - muito embora não esgote o conteúdo de práticas e valores próprios de cada esfera de ação. Com isso, poderíamos dizer que, no primeiro caso, a liberdade jurídica não possui "substancialidade ética" para determinar uma esfera social espacialmente delimitada e, no segundo, que 
ao direito é atribuída uma vinculação substancial com a eticidade potencialmente dispersa ao longo de toda a sociedade, muito embora ela seja dependente dos valores corporificados nas esferas de ação particulares. Em nenhum desses casos, por motivos diversos, poderíamos falar do direito como uma esfera social compartimentalizada. Nesse sentido, Honneth escreve:

Longe de pensar no direito como algum tipo de espaço cercado, eu o trato como um elemento onipresente em nossas sociedades, disponível a qualquer momento como recurso prático e meio compartilhado para rejeitar demandas irracionais, justificar reformas sociais ou dar força institucional a mudanças sociais recém-alcançadas. (...) Mas, principalmente, o que eu pretendi mostrar em $O$ direito da liberdade, com base na filosofia hegeliana, é que se compreende mal as interações entre os participantes dessas várias esferas ao assimilá-las ao modelo de obediência às normas jurídicas. As relações de reconhecimento alcançadas entre os sujeitos são geralmente governadas pelos valores que, segundo concepções compartilhadas, fornecem a essas esferas seu objetivo e propósito. (...) Os limites do direito (e portanto, de qualquer análise social baseada nele) consiste no fato de que ele é incapaz de determinar quais tipos de relacionamento os membros de uma sociedade devem pôr em movimento nas diferentes esferas de ação (Honneth, 2017, p. 128).

Em decorrência disso, o direito tampouco seria capaz de "colonizar" outras esferas de ação em sentido próprio. Como dito anteriormente, o tipo de patologia específica do direito se dá com a generalização unilateral da liberdade jurídica (enquanto liberdade negativa) e o consequente desaparecimento dos modos de cooperação necessários à liberdade social, gerando duas modalidades de distorções no âmbito da eticidade: na primeira delas, a ação deixa de ser conduzida segundo valores, significados e costumes compartilhados, passando a ser estrategicamente calculada em vista do aumento das chances de êxito em um possível litígio futuro; com isso, os sujeitos seriam reduzidos de forma objetivadora ao "somatório de suas reivindicações jurídicas” (Honneth, 2011, pp. 161-166). Na segunda, a própria capacidade de ação se vê comprometida pela manutenção prolongada da atitude suspensiva da liberdade negativa, impedindo a formação da própria vontade e conduzindo a um estado de "postergação de toda decisão profunda" (idem, pp. 167172). Aquilo que Honneth chama de "juridificação" (Verrechtlichung) refere-se ao primeiro desses dois tipos de distorções patológicas da liberdade jurídica (idem, p. 162), sendo que nenhuma das duas modalidades possui o mesmo significado de uma "colonização sistêmica". De acordo com o diagnóstico desenvolvido em $O$ direito da liberdade, se alguma esfera social é explicitamente apresentada como propensa a colonizar as demais, essa é a esfera econômica do mercado - com recursos que podem certamente incluir instrumentos jurídicos, ainda que não derive daí sua lógica de funcionamento (Honneth, 2011, p. 276; Teixeira, 2019, pp. 189-194).

É importante dizer que boa parte das objeções de Scheuerman ao modo controverso como Honneth interpreta o sistema de direitos são de fato pertinentes 
- por exemplo, quando questiona o núcleo "híper-privatista” de sua concepção de direitos subjetivos, o caráter exclusivamente atomizado e estratégico atribuído às competências do direito privado e a subsunção dos direitos sociais a esse mesmo feixe de competências (Scheuerman, 2017, p. 5 ss. [26]). Entretanto, ainda que bastante plausíveis, tais objeções representam uma disputa de interpretações do próprio campo jurídico e dificilmente podem ser convertidas em argumentos contundentes contra o suposto "abandono", "negligência” ou "atitude contrária” ao direito. Scheuerman também parece estar correto ao afirmar que Honneth nunca nos ofereceu contribuições à literatura jurídica especializada tão complexas e abrangentes como Habermas. Ainda assim, por mais sofisticadas que sejam as contribuições da teoria do discurso ao direito e ao Estado constitucional, elas tampouco deixaram de ser fortemente criticadas por limites, lacunas e simplificações notáveis (Rosenfeld, Arato, 1998; Deflem, 2013). Apesar de toda a abrangência e complexidade encontradas por Scheuerman nas análises jurídicas de Habermas, estas se mostram quase que exclusivamente circunscritas a questões de direito constitucional, deixando de lado um número significativo de disciplinas tradicionais e uma infinidade de questões e tópicos do debate jurídico contemporâneo. Desse modo, quando o modelo tomado por Scheuerman como exemplar mostra-se ele próprio bastante seletivo, seus critérios implícitos de abrangência e complexidade técnica perdem significativamente impacto.

Perante o imenso volume e a profunda especialização da literatura jurídica, bem como os processos políticos contínuos e, por princípio, nunca completamente exauríveis de “interpretação constitucional”, parece justificável que a apreensão do fenômeno jurídico pela teoria crítica seja assumidamente seletiva, orientando-se por objetivos delineados no quadro interdisciplinar de problemas sociais prementes em um momento histórico particular (Honneth, 2017, pp. 126-127). Em contraposição a isso, as objeções de Scheuerman a um suposto empobrecimento dos estudos jurídicos pela vertente antilegalista não nos mostra claramente qualquer critério de seletividade, qualquer objetivo específico que justificasse o estudo do direito para fins de crítica e transformação social. O estudo e a aplicação do direito parecem configurar um fim em si mesmo, sendo defendidos como o objetivo maior a subordinar normativa e temporalmente qualquer outro propósito prático-investigativo: “Vamos primeiro criar um planeta em que os direitos fundamentais, a rule of law e o constitucionalismo estejam assegurados. Depois podemos ter uma conversa mais produtiva sobre suas possíveis patologias" (Scheuerman, p. 11 [43]).

III

Pelo exposto, o antilegalismo de Honneth não pode ser tomado como uma atitude contrária ao direito, mas contrária sim à “fixação unilateral” das teorias 
normativas contemporâneas em questões estritamente jurídicas e, sobretudo, a seu efeito de clivagem na agenda de problemas sociais submetidos à avaliação crítica (Honneth, 2017, p. 126). Essa postura, como vimos, não caracteriza uma ruptura com as contribuições da teoria do discurso ao estudo do direito e da democracia constitucional, mas compartilha com ela alguns traços elementares, tais como a atenção constante aos limites próprios do medium direito (salientando sua dependência em relação a uma infraestrutura comunicativa que lhe serve de base e que não pode ser produzida por instrumentos legais), bem como a denúncia de suas ambivalências constitutivas, podendo tanto reforçar como reprimir a liberdade por meio, por exemplo, da institucionalização de privilégios sociais, do isolamento e da segregação legalizada, de regulações paternalistas e de processos de tomada de decisão sem suficiente participação dos concernidos. 0 modo particular como esses componentes são articulados em $O$ direito da liberdade busca inserir o direito em um quadro mais amplo de crítica social baseado na ideia de eticidade democrática, promovendo um tipo de avaliação da história institucional atenta à multiplicidade de fontes normativas corporificadas em esferas de ação descentradas e, sobretudo, focada nas tendências de degeneração de suas estruturas de cooperação reflexiva. 0 direito, nesse sentido, pode servir tanto à institucionalização quanto à desinstitucionalização da liberdade social, corroborando, neste último caso, tendências ideológicas que a consideram "desnecessária, impossível ou perigosa" (Anderson, 2013, p. 19).

Mas se as objeções aqui mencionadas ao antilegalismo de Honneth não parecem atingir a especificidade de sua crítica social, elas também tendem a obscurecer alguns de seus aspectos mais problemáticos. Gostaria de apenas indicar aqui três possíveis linhas de questionamento que merecem ser desenvolvidas do ponto de vista de uma crítica social focada na ideia de eticidade democrática.

Inicialmente, se o programa de pesquisa desenvolvido em $O$ direito da liberdade permite ampliar os estudos sobre democratização social para além do sistema político e do direito positivo, ele também carrega o risco de constrangê-los a um novo tipo de engessamento conceitual. Com efeito, esse projeto parece cunhado de modo ao mesmo tempo pretensioso e redutor, pois procura abranger todas as dimensões de realização da liberdade e, simultaneamente, acomodá-las a um programa teórico preliminarmente limitado a três esferas de cooperação reflexiva. Essa pretensão tem sido atacada por deixar de abranger outras esferas de ação incapazes de ser recobertas pela tríade "relações pessoais", "mercado" e "formação democrática da vontade" - como, por exemplo, a "dimensão estética" ou a "esfera pública global” (Schaub, 2018; Jansen, 2013) - e negligenciar formas de funcionamento das esferas consideradas que não poderiam ser esgotadas pela moldura conceitual oferecida - nesse sentido, Timo Jütten e Bert van den Brink, entre outros, objetam convincentemente que o mercado e as relações pessoais não podem ser inteiramente 
caracterizadas como formas de cooperação reflexiva (Jütten, 2015; Brink, 2013). Honneth assume uma posição ambivalente a respeito dos limites da eticidade: por um lado, os critérios anunciados para a apreensão das dimensões contemporâneas da vida ética (Honneth, 2011, pp. 18-29) são capazes de apontar para um conjunto mais diversificado e complexo de esferas de ação. Por outro, mesmo suas tentativas mais ousadas de atualização preservam um apego insuficientemente justificado à estrutura da Sittlichkeit hegeliana. Essa moldura conceitual tende a criar dificuldades à apreensão do material empírico consultado, sendo considerada um dos principais motivos para o caráter alegadamente impreciso de sua história institucional (Jütten, 2015; Schaub, 2018). Nesse sentido, o cumprimento de um projeto crítico pautado nos bloqueios e retrocessos à democratização social em seu mais amplo alcance parece exigir esforços supervenientes à atualização da eticidade operada no livro de 2011 e, possivelmente, a superação da ideia mesma de um sistema orgânico de esferas institucionais. A noção de liberdade social pode assumir um caráter menos restritivo se operada a partir não de uma imagem holística da sociedade, mas de um programa de pesquisa aberto às capilaridades múltiplas e potencialmente conflitantes da interação social.

Em segundo lugar, no final de $O$ direito da liberdade, Honneth apresenta as lutas sociais como o "motor e o meio de realizar princípios institucionalizados de liberdade” (Honneth, 2011, p. 613). Quer dizer, como o impulso social responsável pelas transformações institucionais de acordo com as reivindicações por liberdade, dando ao conjunto das esferas da eticidade uma qualidade dinâmica e não conservadora. No entanto, esta afirmação parece não se encaixar facilmente no conjunto do livro. A categoria de luta social não foi substancialmente evocada durante a maior parte da reconstrução das diferentes esferas da liberdade social. Em muitos casos, suas transformações parecem creditadas a processos objetivos de diferenciação funcional sem uma intencionalidade política clara. Além disso, a obra não apresenta propriamente uma teoria da luta social e não é evidente se ela ofereceria espaço para tanto. Isso porque o conceito de "instituição" utilizado é significativamente robusto para a formação de subjetividades de acordo com a modulação social de seus objetivos e desejos (idem, pp. 92-93), de modo que os motivos da luta se tornam menos claros ou inesperados. Esse tipo de construção no mínimo deixa fora de foco os conflitos sociais imanentes a cada esfera institucional, sendo considerado responsável por um "déficit político" inédito em sua obra (Melo, 2014; Garcia, 2020). E por consequência, o próprio qualificativo “democrático" acoplado à noção de eticidade se mostra bastante enfraquecido: a democratização é avaliada a partir de critérios que apenas acrescentam às esferas institucionais a exigência de maior "reflexividade" e "inclusão" em suas formas de cooperação preexistentes, sem que as respectivas transformações sejam enfaticamente 
vinculadas a processos de contestação e convencimento públicos. Embora a noção de "liberdade social" nos apresente contribuições significativas para uma interpretação não individualista da liberdade individual, as análises levadas a cabo em $O$ direito da liberdade abarcam de forma apenas marginal o valor específico que uma cooperação igualitária e participativa deve assumir em processos de justificação pública das diferentes esferas institucionais.

Quando nos deparamos com a declaração contundente sobre o papel das lutas sociais nas páginas finais do livro, somos imediatamente incitados a ligálo a seus trabalhos anteriores. Em realidade, espera-se que essa lacuna possa vir a ser superada por algum tipo de integração com a teoria da luta social mais amplamente desenvolvida ao longo da década de 1990. Uma integração mais direta, entretanto, não parece autorizada pelos novos termos de sua teoria: Honneth não faz uma relação explícita entre os dois conceitos de luta, de modo que seu projeto centrado na elaboração de uma teoria da justiça pareça substituir o anterior. Para além das diferenças de conteúdo, a harmonização entre as duas ideias de luta social encontra dificuldades em suas notáveis diferenças metodológicas, uma vez que a "reconstrução normativa" da eticidade democrática não coincide com as dimensões do reconhecimento apreendidas anteriormente por meio de uma "fenomenologia empiricamente controlada". ${ }^{3}$

$\mathrm{E}$ isso nos conduz a um último ponto. Honneth nega explicitamente a continuidade de seu modelo anterior: na tentativa de evitar uma antropologia filosófica naturalista e normativamente exigente, seu projeto fenomenológico parece inteiramente abandonado em favor de uma reconstrução normativa das estruturas institucionais da eticidade (Honneth, 2002; Garcia, 2020). E como consequência, parece se distanciar também de sua pretensão inicial de acessar as experiências intramundanas de desrespeito decorrentes de lesões sociais à identidade pessoal - com as quais pretendia aprofundar os fundamentos sociais de uma teoria crítica baseada na possibilidade de transcendência intramundana. Com este passo, tornase menos claro não apenas o nexo da teoria com uma práxis transformadora (que a categoria da luta social teria por função introduzir), mas também sua relação com a experiência pré-teórica de subjetividades socialmente enraizadas. Quando comparado aos desafios produzidos por objeções semelhantes ao projeto de uma fenomenologia política, autoras como Iris Young mostram maior capacidade de combinar a experiência subjetiva de sofrimento e resistência política com elementos de justiça institucional segundo os termos de uma "visão binocular" (Lima e Silva;

\footnotetext{
3 Ricardo Crissiuma tem realizado contribuições importantes para explicitar o modelo de luta social presente em $O$ direito da liberdade e ampliar a percepção de seu papel ao longo da produção mais recente de Honneth. Entre outros trabalhos, conferir neste volume "Reconstrução e indignação: Sobre as modulações da crítica e o potencial transformador do último modelo de Teoria Crítica de Axel Honneth".
} 
Silva, 2017). Na ausência dessa conexão, uma teoria da justiça que busque ir além da gramática jurídica perde acesso a uma diversidade ampla de questões normativas que não alçaram ainda o plano das disputas institucionais, mas se mostram perceptíveis na forma de experiências subjetivas institucionalmente situadas (Young, 2000).

\section{IV}

Por fim, gostaria de chamar atenção para certos desenvolvimentos de Scheuerman em seu novo livro sobre Desobediência civil (2018) - uma obra que, para além da rica exposição do debate já sedimentado sobre o tema, assume um caráter diretamente propositivo, oferecendo-nos teses originais dirigidas a suas formas de continuidade no debate político contemporâneo. Em conclusão, busco defender que a cruzada antilegalista de Scheuerman encontra-se em descompasso com os próprios referenciais teóricos valorizados nesta obra, gerando sobretudo dificuldades à pretendida atualização do conceito à luz da experiência política recente.

Como o próprio Scheuerman admite, a desobediência civil nos coloca sempre em contato com uma normatividade que não se exaure plenamente na positividade do direito, remetendo-nos, em seus próprios termos, a um desrespeito publicamente justificado a leis ou ordens estatais em nome de um “direito superior". Na primeira parte da obra, dedicada ao desenvolvimento teórico do conceito, Scheuerman nos apresenta quatro principais modelos de desobediência civil: os modelos religioso, liberal, democrático e anarquista. Para o autor, poderíamos encontrar um "processo de aprendizagem" positivo no desenvolvimento dos três primeiros, partindo da consolidação dessa forma de protesto com base em uma normatividade de fundo espiritual, seguindo com a depuração e decorrente substituição da lei divina por princípios de justiça constitucionalmente assegurados para, enfim, alcançar exigências mais amplas de um procedimento democrático igualitário e inclusivo. Diferentemente do modelo liberal, que transformaria a desobediência civil em um mecanismo para a recomposição de garantias constitucionais violadas, Scheuerman encontra em Arendt e Habermas um modelo proeminentemente político, transformativo, dedicado à denúncia de procedimentos democráticos falhos e, sobretudo, ao "aprofundamento da democracia” (Scheuerman, 2018, cap. 3). Para Scheuerman, entretanto, esse processo de aprendizado contínuo, com ganhos cumulativos no desenvolvimento de sua normatividade própria, seria substancialmente ameaçado pela vertente anarquista: seu anti-legalismo militante desvincularia a desobediência civil de qualquer comprometimento claro com o Estado democrático de direito, conduzindo a uma "desdiferenciação conceitual" em relação a outras formas de protesto e, fundamentalmente, a "consequências políticas desagradáveis", por abrir mão de seu apelo simbólico e sua reconhecida capacidade de justificação pública. Na segunda parte da obra, Scheuerman aborda o ressurgimento da desobediência civil como 
categoria crescentemente reivindicada por protestos políticos nas últimas décadas, salientando diferenças significativas em seu formato e novos desafios gerados a sua avaliação teórica. Entre as características mais marcantes no novo contexto, Scheuerman salienta a "pós-nacionalização e privatização" - isto é, a inserção da desobediência civil no cenário de protestos globais dirigidos prioritariamente não a autoridades políticas tradicionais do Estado-nação, mas a agentes e instituições econômicas internacionais - bem como uma adesão recorrente e, segundo o autor, "perigosa", a um autocompreensão anarquista.

Independentemente dos muitos méritos da obra, é necessário inicialmente perceber que ambos os autores aos quais Scheuerman atribui o desenvolvimento de seu modelo privilegiado - vale dizer, o modelo democrático de desobediência civil não compartilham o mesmo tipo de recusa ao antilegalismo; muito pelo contrário, arrolam entre seus principais adversários as posições legalistas encontradas nos respectivos contextos de análise. No ensaio "On Civil Disobedience", de 1970, Arendt explicitamente se opõe às compreensões morais e legalistas deste conceito, as quais encontrariam suas bases respectivamente na consciência individual ou no grau hierárquico superior da lei constitucional (Arendt, 2010, pp. 52-55). Para a autora, uma compreensão política de desobediência civil a considera baseada não em uma lei escrita qualquer, mesmo que de estrato superior, mas sim no "espírito das leis", o que nos remeteria às condições histórico-sociais do pacto político e aos princípios subjacentes a uma "sociedade do consentimento" (Arendt, 2010, p. 75, ss.); Habermas, por sua vez, combate a posição legalista como contraditória e potencialmente autoritária: a desobediência à lei não poderia ser autorizada por lei (se o fosse, não seria propriamente uma desobediência); mais importante, a posição legalista transformaria aquelas que protestam contra leis e atos governamentais ilegítimos em criminosas comuns, colocando-as fora do jogo político. E contrariamente à tese de que a desobediência civil não seria aceita no estado de direito alemão por não se encontrar formalmente reconhecida via legislação ou jurisprudência constitucional, Habermas encontra seu enraizamento não propriamente no texto escrito de normas e decisões judiciais, mas em uma "cultura política democraticamente desenvolvida" (Habermas, 2015, p. 144).

Ainda assim, ambos os autores permanecem presos ao quadro de pressupostos westfalianos, sendo incapazes de abarcar satisfatoriamente o deslocamento histórico das experiências concretas de protesto contra instâncias do poder econômico de estrutura transnacional. Scheuerman parece estar atento a esta dificuldade. Embora defenda Arendt e Habermas no plano teórico, o autor não faz uso do referido modelo democrático quando se dedica às novas práticas de desobediência civil. Ao invés disso, reclama a centralidade de uma interpretação universalista e moralmente carregada da rule of law, inspirada sobretudo na obra de Lon Fuller. Segundo ele, o 
estado de direito expressa o "compromisso normativo de tratar aqueles aos quais nos encontramos vinculados de maneira minimamente respeitosa e digna", ao passo que seu enfraquecimento "ameaça destruir os elementos básicos de nossa personalidade moral" (Scheuerman, 2018, pp. 128-129). Além de contrastar com posicionamentos explícitos dos autores aos quais atribui o modelo dedicado ao "aprofundamento democrático", a inscrição desse componente moral substancialista da rule of law nos capítulos finais do livro possui um caráter ad hoc, sem qualquer relação com as reconstruções iniciais sobre as bases normativas imanentes à desobediência civil.

Muito embora Honneth não faça uso direto do conceito, uma visitação a sua crítica social poderia ajudar neste ponto. Por um lado, a relação feita entre reconhecimento jurídico e personalidade moral, como vimos, é bastante explorada pelo autor. Entretanto, essa relação não é vista como decorrência de uma concepção ideal da rule of law (defendida por Scheuerman sem um ancoramento empírico explícito, de forma historicamente negligente e tendencialmente apolítica). Em Honneth, esse vínculo entre reconhecimento jurídico e personalidade moral é estabelecido por meio de processos históricos de lutas por direitos que ampliam as qualidades morais a serem reciprocamente atribuídas a todos os membros de uma comunidade jurídica, denunciando tanto a insuficiência do conteúdo de direitos compartilhados quanto a exclusão injustificada de indivíduos e grupos como membros plenos da comunidade jurídica. Nesse sentido, é importante notar que o maior exemplo de luta por reconhecimento jurídico utilizado por Honneth em 1992 referese ao movimento por direitos civis nos EUA (Honneth, 2001, p. 198), um dos casos históricos mais emblemáticos de utilização da desobediência civil como categoria nativa em processos políticos concretos.

Além disso, a ampliação do foco da desobediência civil em direção a instâncias econômicas, principalmente relacionadas a agentes e instituições transnacionais do mercado financeiro, parece se beneficiar heuristicamente da tese honnethiana que defende a impregnação normativa da economia, trabalhada por ele de diferentes formas ao longo de sua obra (Honneth, 2001; Honneth, 2011). Vale dizer que Nancy Fraser, colocada ao lado de Honneth como uma uma das maiores representante das tendências antilegalistas na teoria crítica contemporânea, também assume uma versão particular desta tese, voltando-se às demandas por novos enquadramentos (frames) de representação política no plano da justiça transnacional (Fraser, 2010). Cabe admitir que os modos como essa tese geral é delineada por Honneth e Fraser não são idênticos ou incontroversos; ainda assim, em face da "privatização e pósnacionalização" das autoridades contestadas (identificadas por Scheuerman como características centrais das novas dinâmicas de protesto), parece produtivo trabalhála como uma hipótese de sentido aberto, voltada a compreender os modos como a suposta normatividade impregnada no mercado tem sido mobilizada em protestos 
dirigidos contra organizações do capitalismo financeiro, bem como que tipo de exigências democratizantes podem ser ali identificadas.

Para finalizar, cabe dizer que a cruzada antilegalista de Scheuerman o faz negligenciar transformações significativas na autocompreensão de agentes políticos que reivindicam a desobediência civil como categoria tanto explicativa quanto justificatória. Como o próprio autor admite, o ressurgimento recente do debate teórico sobre o tema se deve em grande medida à notoriedade desta forma de ação política em protestos globais desencadeados pela crise financeira de 2008, bastante vinculados a uma gramática de ocupação de espaços públicos que se difundiu em diferentes partes do mundo. Em razão de sua retórica antilegalista, entretanto, Scheuerman qualifica tais movimentos como regressivos, potencialmente violentos e politicamente irresponsáveis, abandonando assim qualquer abertura epistêmica para novos processos de aprendizagem à luz da experiência política recente. Com isso, o autor não apenas negligencia a autocompreensão produzida por ativistas, como busca oferecer a eles recomendações ou direcionamentos pautados em um modelo teórico moralmente exigente - incitando-os sobretudo a demostrar publicamente maior "fidelidade à lei" (Scheuerman, 2018, pp. 132-137). Como já salientou Gabriel Busch de Brito, a obra neste ponto acaba recaindo em uma "sobreposição da teoria em relação à prática muito problemática para um projeto que se compreende como pertencente ao campo da teoria crítica" (Brito, 2019, p. 5). E em função mesmo da referida sobreposição teórica, Scheuerman torna seu projeto de atualização impermeável à autocompreensão e justificação normativa de agentes que reclamam a desobediência civil no registro dos chamados "novos anarquismos" (Gerbaldo, 2017; Bray, 2013; Graeber, 2002). Em um texto intitulado "The new anarchists", intencionalmente dedicado ao combate de mal-entendidos em relação à dinâmica interna de Occupy Wall Street, David Graeber nos remete explicitamente à tentativa conjunta de estabelecer uma "nova linguagem à desobediência civil", a qual seria "não-violenta, ainda que em sentido distinto do autossacrifício de Gandhi", e vinculada sobretudo à produção de formas não hierárquicas de uma "democracia do consenso":

[E]sse é um movimento que se propõe a reinventar a democracia. Ele não se opõe à organização. Trata-se, ao contrário, de criar novas formas de organização. E isso não significa também ausência de ideologia. Essas novas formas de organização são sua ideologia. Trata-se de criar e promulgar redes horizontais ao invés de estruturas organizativas de cima para baixo, como Estados, partidos ou corporações; vale dizer, trata-se de desenvolver redes baseadas em princípios descentralizados de uma democracia consensual não hierárquica (Graeber, 2002, p. 70).

Esse tipo de posicionamento, caso não seja considerado um esforço isolado, nos confere bons indícios de que a autorreflexão anarquista pode não apenas ser 
compatível com o chamado "modelo democrático" da desobediência civil, mas contribuir em seu desenvolvimento para além do estado deixado por Habermas desvelando seu admitido “cerne anárquico" e combinando o componente deliberativo até então predominante com práticas espontâneas de participação não hierárquica, cooperação igualitária e resistência pacífica, embora não sacrificial.

\section{Referências}

Anderson, J. (2013). The fragile accomplishment of social freedom. Krisis. Journal for Contemporary Philosophy, 1, 18-22.

Bray, M. (2013). Translating Anarchy: The Anarchism of Occupy Wall Street. Winchester: Zero Books.

Brink, B. (2013), From personal relations to the rest of society. Krisis. Journal for Contemporary Philosophy, 1, 23-27.

Brito, G. B. (2020). Desobediência civil entre pós-nacionalização e digitalização. Dissonância: Revista de Teoria Crítica, AOP (Advance Online Publication).

Deflem, M. (2013). “The Legal Theory of Jürgen Habermas”. In: Banakar, R.; Travers, M. Law and Social Theory. Oxford: Hartman Publishing.

Fraser, N. (2010). Scales of Justice: Reimagining Political Space in a Globalizing World. New York: Columbia University Press.

Garcia, R. (2020). Crítica Reconstrutiva em Axel Honneth. Dissertação (Mestrado em Filosofia) - Universidade Federal do Rio Grande do Sul. Porto Alegre.

Gerbaldo, P. (2017). The Mask and the Flag. Populism, Citizenism and Global Protest. Oxford: Oxford University Press.

Graeber, D. (2002). The New Anarchists. New Left Review, 13, 61-73.

Habermas, J. (1992). Faktizität un Geltung. Beiträge zur Diskurstheorie des Rechts und des demokratischen Rechtsstaats. Frankfurt a. M.: Suhrkamp. [Idem, (2020). Facticidade e validade. Trad. Felipe Silva e Rúrion Melo. São Paulo: Ed. Unesp]

Habermas, J. (2015). A Nova obscuridade. Pequenos escritos Políticos V. São Paulo: Ed. Unesp.

Honneth, A. (2001). "Redistribution as Recognition: a response to Nancy Fraser". In: Fraser, N. Honneth, A. Redistribution or Recognition. A Political-Philosophical Exchange. London: Verso.

Honneth, A. (2002). Grounding Recognition: A Rejoinder to Critical Questions. Inquiry, 45, 499-520. DOI: https://doi.org/10.1080/002017402320947577

Honneth, A. (2003). Luta por reconhecimento: A Gramática Moral do Conflitos Sociais. São Paulo: Editora 34.

Honneth, A. (2007a). "Democracy as Reflexive Cooperation: John Dewey and the Theory of Democracy Today." In: Disrespect: The Normative Foundations of Critical Theory. Cambridge: Polity Press.

Honneth, A. (2007b). "The social dynamics of disrespect: on the location of critical theory today". In: Disrespect: The Normative Foundations of Critical Theory. Cambridge: Polity Press. 
Honneth, A. (2011). Das Recht der Freiheit: Grundriss einer demokratischen Sittlichkeit. Frankfurt/A: Suhrkamp.

Honneth, A. (2017). Beyond the Law: A Response to William Scheuerman. Constellations, 24(1), 126-132. DOI: https://doi.org/10.1111/1467-8675.12272

Jansen, Y. (2013) The 'Us' of democratic will-formation and globalization. Krisis. Journal of Contemporary Philosophy, 1, 32-36.

Jütten, T. (2015) Is the Market a Sphere of Social Freedom?. Critical Horizons, 16(2), 187-203. DOI: https://doi.org/10.1179/1440991715Z.00000000047

Lima e Silva, G.; Silva, F. (2017). "Between experience and structure: Social suffering, collective identities and justice in Iris Marion Young". In: Bueno, A.; Teixeira, M. (orgs.). On the politics of social suffering. Digithum, 23, Barcelona.

Melo, R. S. (2014). Da teoria à práxis? Axel Honneth e as lutas por reconhecimento na teoria política contemporânea. Revista Brasileira de Ciência Política, 15, 17-36. DOI: https://doi.org/10.1590/0103-335220141502

Rosenfeld, M.; Arato, A. (1998). Habermas on Law and Democracy: Critical Exchanges. Berkeley: University of California Press.

Schaub, J. (2018). Aesthetic freedom and democratic ethical life: A Hegelian account of the relationship between aesthetics and democratic politics. European Journal of Philosophy, 27(1). DOI: https://doi.org/10.1111/ejop.12403

Scheuerman, W. (2017). Recent Frankfurt Critical Theory: Down on Law? Constellations, 24(1), 113-125. DOl https://doi.org/10.1111/1467-8675.12218 [A teoria crítica frankfurtiana recente: Avessa ao direito?. Tradução Bianca Tavolari. Dissonância: Revista de Teoria Crítica, 2018].

Scheuerman, W. (2018). Civil Disobedience. Malden: Polity Press.

Tavolari, B. M. D. (2019). Origens da juridificação: direito e teoria crítica. Tese (Doutorado em direito) - Universidade de São Paulo, São Paulo.

Teixeira, M. (2019). "Can Honneth's Theory Account for a Critique of Instrumental Reason? Capitalism and the Pathologies of Negative Freedom". In: Schmitz, V. (ed.). Axel Honneth and the Critical Theory of Recognition. London: Palgrave Macmillan.

Young, I. (2000). Inclusion and Democracy. Oxford: Oxford University Press.

Esta obra está licenciada com uma Licença Creative Commons Atribuição-NãoComercial-Compartilhalgual 4.0 Internacional.

https://creativecommons.org/licenses/by-nc-sa/4.0/

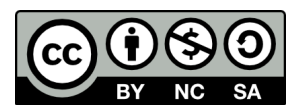

